To be published in Applied Optics:

Title: $\quad$ Visual and instrumental correlation of sparkle by the magnitude estimation method

Authors: $\quad$ Omar Gomez,Esther Perales,Elisabet Chorro,Valentin Viqueira,Francisco Martínez-Verdú Accepted: 15 July 16

Posted 19 July 16

Doc. ID: 267073 


\title{
Visual and instrumental correlation of sparkle by the magnitude estimation method
}

\author{
Omar Gómez* , Esther Perales, Elísabet Chorro, Valentín Viqueira, \\ FRANCISCO M. MARTÍnEZ-VERdú
}

Color \& Vision Group, University of Alicante, Carretera de San Vicente del Raspeig s/n 03690, Alicante, Spain

*Corresponding author: omar.gomez@ua.es

Received XX Month XXXX; revised XX Month, XXXX; accepted XX Month XXXX; posted XX Month XXXX (Doc. ID XXXXX); published XX Month XX

\begin{abstract}
Most real surfaces and objects show variation in appearance with viewing and illumination directions. Besides angular dependency, they also show spatial variation in color; i.e. they exhibit some sort of texture. Of the surfaces we see, surfaces colored by special-effect pigments produce several complex visual effects, like change in color and lightness with viewing and illumination angles, and effects like sparkle and gloss on other textures.
\end{abstract}

In the last two decades, different commercial devices have appeared to help ensure the proper characterization of materials with special-effect pigments. However, the instrumental characterization of sparkle is currently available only by a commercial device integrated into a multi-angle spectrophotometer. As it is difficult to find complete open original studies about the sparkle effect for designing and calibrating this commercial instrument, the main objective of this work was to check whether a good visual and instrumental correlation exists between the sparkle that the observer perceives and the sparkle value provided by the device using some subsets of goniochromatic samples with different types of special-effect pigments and colors. Visual assessments were made by a conventional magnitude estimation method in a directional lighting booth, which belonged to the same company owner of the sparkle instrument, in different geometries and at distinct illuminance levels.

The results revealed that there was a good visual correlation of the sparkle-grade value. By separately analyzing the factors used in its instrument algorithm, such as sparkle intensity and sparkle-area values, it was clearly shown that the correlation was not good or simply did not exist. Consequently, and perhaps as regards choice of new special-effect pigments, such as synthetic mica and other future ones, we generated herein even more questions about current mathematical algorithms, and only recognized calculating this texture effect at the industrial level.

OCIS codes: (999.9999) Sparkle; (330.1880) Detection; (330.5020) Perception psychology; (330.5510) Psychophysics; (150.3040) Industrial inspection

http:// web.ua.es/gvc

\section{INTRODUCTION}

In many coloration industries (cosmetics, plastics, etc.), especially the automotive industry, there is an increasing trend to use special-effect pigments (metallic, interference, or even diffractive effects) in automotive coatings to reinforce the attractive appeal of car bodies. Automotive coatings are composed mainly of an ordered mixture of conventional pigments and flakelike pigments in parallel to the exterior surface to produce smooth or abrupt changes in color and texture according to illumination and viewing directions [1]. Depending on the geometric nature of lighting, we can perceive sparkle under directional conditions, or graininess under diffuse conditions, or even both combined under most realistic lighting conditions.
The current official definition of sparkle by ASTM E-284 [2] is: "the aspect of the appearance of a material that seems to emit or reveal tiny bright points of light that are strikingly brighter than their immediate surround and are made more apparent when a minimum of one of the contributors (observer, specimen, light source) is moved". Therefore, under direct illumination conditions such as bright sunlight, flakes in a metallic finish glitter to create a sparkling effect. Tiny bright sparkles of light that vary in intensity can be seen, similarly to stars in the night sky. The sparkling effect on metallic finishes is so striking that other micro-appearance aspects are lost while observing it. Under diffused illumination, e.g. a cloudy sky, metallic finishes do not have the sparkling effect. Instead they may create a salt-and-pepper effect, a light dark pattern. This effect can be referred to as graininess or coarseness. 
Both sparkle and graininess depend on flake size, orientation and distribution [3-5]. In particular, only those flakes whose orientation makes them act as specular reflectors at a particular geometry will generate a sparkle point. Metallic finishes with larger coarse flakes show intense sparkle, while those with very fine flakes appear uniform, almost like a uniform color. Currently, there is only one instrument on the market that measures effects of texture, the BYK-mac $\AA$ multi-angle spectrophotometer [6]. Besides having six measurement geometries for characterizing goniochromism, this instrument has a CCD monochrome camera that acts as a detector for texture measurements. The sample is illuminated directionally under $15^{\circ}, 45^{\circ}$ and $75^{\circ}$ as regards what is normal on the sample surface. The photographed gray-scale pictures are internally used to calculate texture parameters. In particular for the sparkle effect, three different parameters are given, sparkle intensity $\left(\mathrm{S}_{\mathrm{i}}\right)$, sparkle area $\left(\mathrm{S}_{\mathrm{a}}\right)$ and sparkle grade $\left(\mathrm{S}_{\mathrm{G}}\right)$, for the three directional geometries.

However, the mathematical and optical algorithm to measure and calculate the sparkle grade $\left(\mathrm{S}_{\mathrm{G}}\right)$ implemented by the BYKGardner company is neither publicly known nor regulated by international regulations like ISO, ASTM or DIN. So many questions about texture effect remain [5]: visual detection distance, measurement geometries, influence of illuminance level, effect of the spectral distribution of the light source employed, discrimination tasks vs. grading, influence of the color sample (hue, lightness or chroma), etc. Although these new texture effects are important for the visual appearance of many materials, very few studies have addressed these issues [7-13]. The only mathematical relationship known about the algorithm used in BYK-mac is the following equation:

$$
S_{G}=0.35 * \sqrt{\left(S_{i} * S_{a}\right)}-0.8
$$

Regarding this formula, it is not exactly known how sparkle intensity $\left(\mathrm{S}_{\mathrm{i}}\right)$ or sparkle area $\left(\mathrm{S}_{\mathrm{a}}\right)$ is calculated, although it is known both are obtained by histogram imaging analysis,. Nor is it known from where these two numerical factors are deducted. Yet there are models that attempt to simulate these parameters [14] because it is a BYK-Gardner patent [15]; as described above, nothing has been revealed to relate it to sparkle texture effect calculations. So there are still many questions that cannot be answered.

The BYK-mac Project emerged from the alliance formed by companies Akzo Nobel Coatings, BYK-Gardner and Merck. This project, called Total Appearance Research BYK-Gardner, Akzo Nobel, Merck (TARBAM), was led by Akzo Nobel Coatings [16], and was developed for both the design and mathematical algorithm, along with visual validation, based on a large set of samples with many goniochromatic pigments known in the automotive industry. Ever since that time, new types of effect pigments with very different characteristics have emerged that produce new texture effects.

Therefore, given the lack of open technical information, no available international standards about sparkle, and new trends in special-effect pigments for visual texture in automotive coatings, not even for other industries (cosmetics, plastics, etc.), the purpose of this work was to test the visual and instrumental correlation of sparkle.

\section{MATERIALS AND METHODS}

Ninety-one samples with metallic and interference pigments from different suppliers were used (BASF Coatings, Eckart, Merck). For most samples, the exact pigment recipes were not known (type and shape of pigment, concentration, etc.). Knowing this information for this experiment was not necessary as this work focused on visual and instrumental correlations, and not on evaluating the influence of pigment formulation (and coating application process) on texture appearance. From the partial technical information we have about them, pigment type and particle size ( $\left.D_{50}\right)$ ranged from $9 \mu \mathrm{m}$ to $92.5 \mu \mathrm{m}$ (Table 1). So we covered all the possible pigments sizes and did not rely solely on the pigment sizes that the automotive industry conventionally uses. The influence of color on sparkle detection and scaling (grade) is not included herein. The instrumental data of the samples provided by BYK-mac are shown below (Figure 1). For simplicity reasons, sparkle area and intensity are summarized as one value: sparkle grade. Sparkle grade is represented by the colored lines in the diagram from $S_{G}=0$ to $S_{G}=20$. Most of the four subsets were kindly provided by some stakeholders, particularly those which collaborated in the xD-Reflect European project (http://www.xdreflect.eu/ ). In addition, subset no. 4 is basically a mix of Luxan pigment (synthetic mica) with fixed black pigment.

\begin{tabular}{ccccc}
\hline & Number & Pigment Type & $\begin{array}{c}\text { Pigment } \\
\text { Size }\end{array}$ & $\begin{array}{c}\text { Color } \\
\text { Background }\end{array}$ \\
\hline $\begin{array}{c}\text { Set 1 } \\
\text { (BASF) }\end{array}$ & 29 & Interference & No Data & Variable \\
$\begin{array}{c}\text { Set 2 } \\
\text { (Merck) }\end{array}$ & 30 & Interference & $9-25.5 \mu \mathrm{m}$ & Variable \\
$\begin{array}{c}\text { Set 3 } \\
\text { (Merck) }\end{array}$ & 10 & Metallic & $9-35 \mu \mathrm{m}$ & Silver \\
$\begin{array}{c}\text { Set 4 } \\
\text { (Eckart) }\end{array}$ & 22 & Slakes & & \\
\hline
\end{tabular}

Table 1: Subsets of the goniochromatic samples used herein.
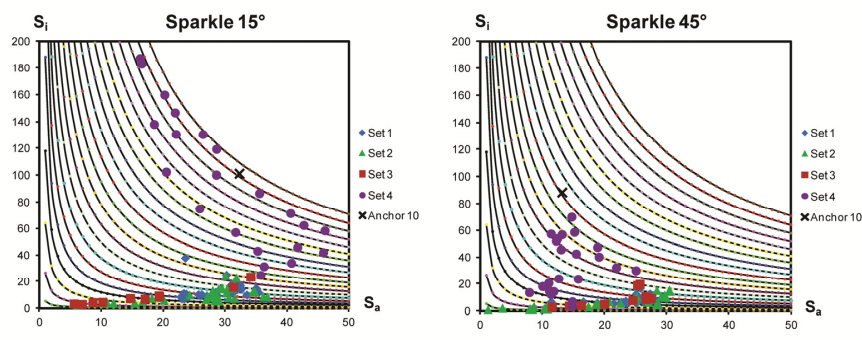

Figure 1: Distribution of the four subsets into conventional sparkle graphs.

To run the psychophysical experiment, a directional lighting booth was used, which also belonged to the same company as BYK-mac, commercially known as a byko-spectra cabinet [17]. 
Two measuring geometries were used, $15^{\circ}$ as $15^{\circ}, 45^{\circ}$ as $45^{\circ}$, following the ASTM standards nomenclature, or $15^{\circ} \mathrm{x}: 0^{\circ}$ and $45^{\circ} \mathrm{x}: 0^{\circ}$, following the CIE nomenclature [18], and two illuminance levels, 800 and 2400 lux [19]. These two measurement geometries were used to see how the orientation of pigments impacted sparkle because we hypothesized that the flakes seen in the $15^{\circ}$ as $15^{\circ}$ and $45^{\circ}$ as $45^{\circ}$ geometries corresponded to those that were well-ordered as regards the outer surface. However, the flakes perceived in the $75^{\circ}$ as $75^{\circ}$ geometry were not parallel to the surface [10]. The two illuminance levels were used to test how light intensity impacted sparkle grading. It is noteworthy that the byko-effect cabinet was selected because it enabled us to make visual assessments with the same three measurement geometries found in BYK-mac.

Experiments were held in a dark room, and each observer 5 minutes in the cabinet environment for luminous adaptation purposes. In addition, a mask was used into the cabinet for the visual assessments, in which two anchors are set (relative minimum and maximum sparkle grade) depending on the instrumental value of sparkle provided by the BYK-mac. A mask was used inside the cabinet for the visual assessments, in which two anchors were set (relative minimum and maximum sparkle grades) depending on the instrumental sparkle value provided by BYK-mac. The display area of the anchors and the sample was $6 \times 6$ $\mathrm{cm}$ (Figure 2). The distance between the center of the test sample and the observer was equal to $52 \mathrm{~cm}$ by fixing the measuring geometries described above. Samples were randomly presented to the observers during 30-minute sessions to help them concentrate as constantly as possible, and to avoid changes due to fatigue. Before each session, a clear description about the sparkle concept was shown to each observer,

For this visual experiment, 11 observers participated $(7$ men and 4 women, aged from 25-55 years). Each observer did three repetitions per sample, in each geometry and at both illuminance levels, and 1.104 visual assessments were obtained by each observer. For this experiment, 12.144 visual assessments were made in all.

The conventional magnitude estimation method was used only for this visual experiment [20-21] with samples (or stimuli) above the threshold. Observers are asked to assign numbers in proportion to the magnitude of the stimulus (anchor). This method was selected as there are very few psychophysical experiments available on the sparkle texture effect, and it can be easily used by observers with or without previous experience in the visual appearance of materials. All the observers freely decided about the final sparkle grade assessment without knowing the exact combination of the partial sparkle attributes (Eq. 1).

Based on these two anchors, observers made assessments with values between 0 and 10, but were also free to assess with values above 10 if they thought that the sample in the center had a better sparkle value than the maximum anchor sample. The instrumental values of the maximum sparkle grade of both anchors (not identical) for both geometries were $\mathrm{S}_{\mathrm{G}_{-}} 15=19.22$ and $\mathrm{S}_{\mathrm{G}_{-}} 45=$ 11.14 .
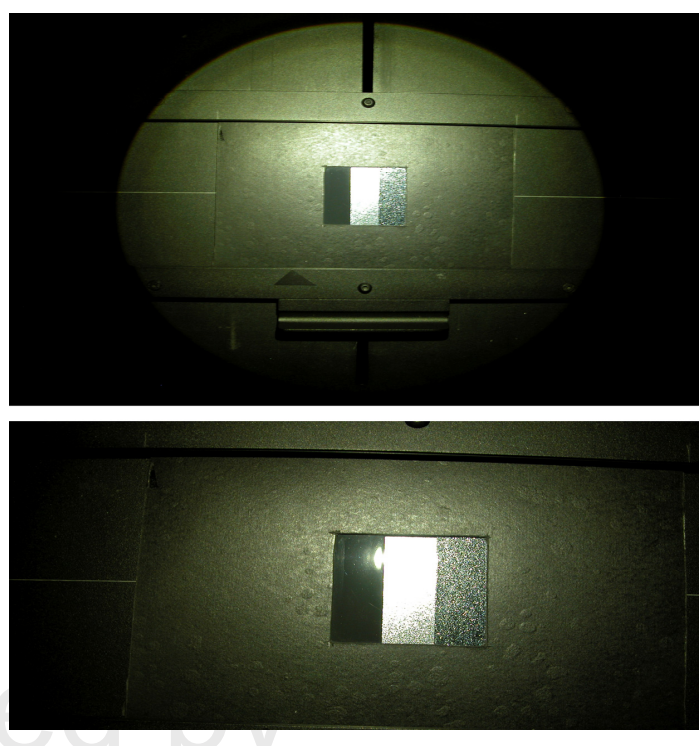

Figure 2: Reference samples (anchors) with the mask used to carry out the psychophysical sparkle estimation experiment.

The STRESS Index (standardized residual sum of squares), which is usually applied for testing color difference formula [2224], was also used herein to compute intra- and inter-observer variability. As a result, the lower the STRESS values, the better the correlation. Intra-observer variability refers to the differences between the results obtained when the same observer reported the same issue more than once. It was measured by the STRESS Index, and was calculated from three repetitions for each observer in the same experiment. Inter-observer variability refers to differences between the results obtained by several observers. It was also calculated by the STRESS Index by considering the total average of the 11 observers and the mean value of three replicates of each observer. As measurements of perceived texture differences are always subjective, these measurements have non negligible uncertainty, which must be taken into account.

\section{RESULTS}

The psychophysical assessments and instrumental data allowed us to determine the instrumental and visual correlation as regards the experiment carried out.

\section{Observer Variability}

The average intra-observer variability obtained in this experiment was 9.45 STRESS units and the average inter-observer variability was 18.87 STRESS units. When we analyzed the results, the $15^{\circ}$ as $15^{\circ}$ geometry obtained a better inter-observer correlation than the $45^{\circ}$ as $45^{\circ}$ geometry, although all the calculated values were good compared with other studies on color differences [25].

\section{Visual and Instrumental Correlation}

$\mathrm{S}_{\mathrm{G}} \mathrm{vs} \mathrm{VS}_{\mathrm{G}}$ : general correlation, and influence of illuminance and geometry.

The visual $\left(\mathrm{VS}_{\mathrm{G}}\right)$ and instrumental $\left(\mathrm{S}_{\mathrm{G}}\right)$ sparkle texture effect correlation was studied to test whether BYK-mac predicted what the observer perceived. Different visual assessments were made by varying the measurement geometry and illuminance level. For 
the same illuminance level and a different geometry, the visual and instrumental sparkle correlation estimation was almost equal for a low illuminance level (800 lux) (Figure 3). However for a higher illuminance level (2400 lux), sparkle was slightly better scaled in the $45^{\circ}$ as $45^{\circ}$ geometry (Figure 4 ). In summary, a good visual and instrumental correlation was obtained for both geometries and illuminance levels.
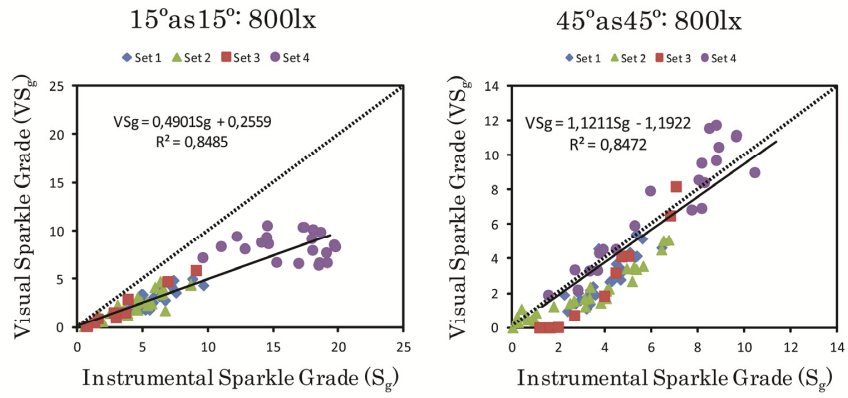

Figure 3: Sparkle grade correlation for the low illuminance conditions (800 lux) for the $15^{\circ}$ as $15^{\circ}$ (left) and $45^{\circ}$ as $45^{\circ}$ (right) measurement geometries.
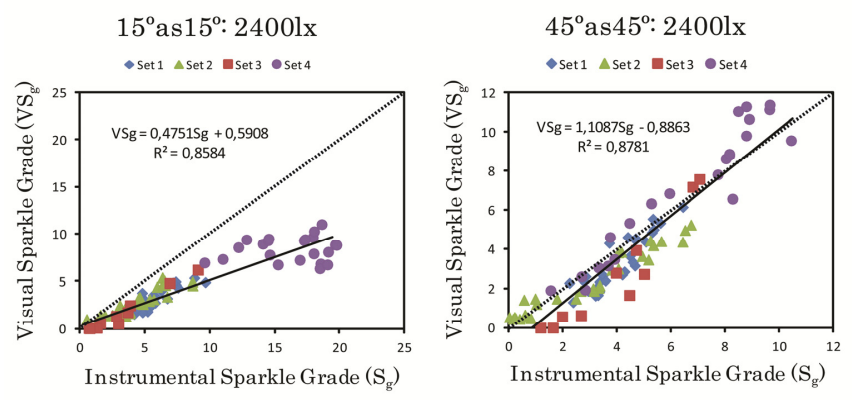

Figure 4: Sparkle grade correlation for the light illumination conditions (2400 lux) for the $15^{\circ}$ as $15^{\circ}$ and $45^{\circ}$ as $45^{\circ}$ measurement geometries.

When comparing geometries and illuminance levels, the slopes in $45^{\circ}$ as $45^{\circ}$ for both the illuminance levels came close to unity, but were approximately half in $15^{\circ}$ as $15^{\circ}$. One suggestion for this was that the original design and validation of BYK-mac was only done for the $45^{\circ}$ as $45^{\circ}$, and with 2400 lux or slightly lower. This seems possible because the range of sparkle values for subsets 1-3 in the $15^{\circ}$ as $15^{\circ}$ geometry was well-grouped compared with subset 4 (Figure 3, left), and within a sparkle range below a value of 10 , which was also seen in the $45^{\circ}$ as $45^{\circ}$ geometry (Figure 4 , right); that is, the sparkle algorithm implemented in the commercial instrument could be conditioned by the initial choice of samples, particularly the types and sizes of the special-effect pigments.

For all cases, including the samples provided by Eckart (Luxan pigment, set 4) and given its formulation, big sizes and high concentrations of pigments were above those of other samples and were not characteristic of the automotive industry. When checking the figures, the estimation made by the observers was quite good compared to the instrumental data provided by BYK-mac.
The $\mathrm{S}_{\mathrm{i}} \mathrm{vs} \mathrm{VS}_{\mathrm{G}}$ : correlation predictability from sparkle intensity value.

In this section, the correlation was studied by taking the sparkle intensity value into account. This parameter is defined according to standard [2] as: "the contrast between the appearance highlights on the particles of a gonioapparent pigment and their immediate surround". Therefore, the sparkle visual evaluation was compared with the sparkle intensity made by the instrument. Note that the only visual assessment requested from observers was a personal balance between sparkle intensity and area values, without them knowing its interplay (Eq. 1). For all the geometry configurations and illuminance levels, applying linear regression was not possible as in the previous section, as expected considering Eq. 1. As cited above, of the 91 samples, Luxan samples had quite different characteristics to the other samples. In particular, the sparkle intensity values obtained for these samples were considerably higher than for the others (when Set 4 was considered, observer saturation occurred; i.e., there was no a linear relationship between both parameters; it was not a case of the more strongly the pigment reflected, the better the observer detected it; this could be due to limitations in human visual acuity). The results are shown in Figures 5 and 6 . At around a value of $S_{\mathrm{i}} \approx$ 40-50, the visual estimations followed a downward pattern.
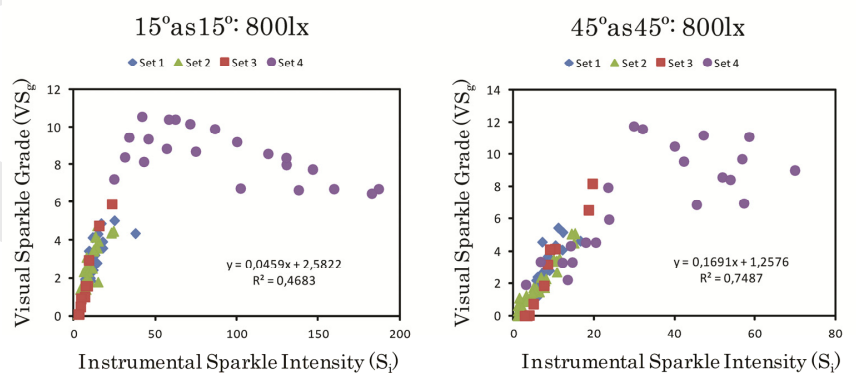

Figure 5: Sparkle intensity correlation for low illumination conditions (800 lux) for the $15^{\circ}$ as $15^{\circ}$ and $45^{\circ}$ as $45^{\circ}$ measurement geometries.
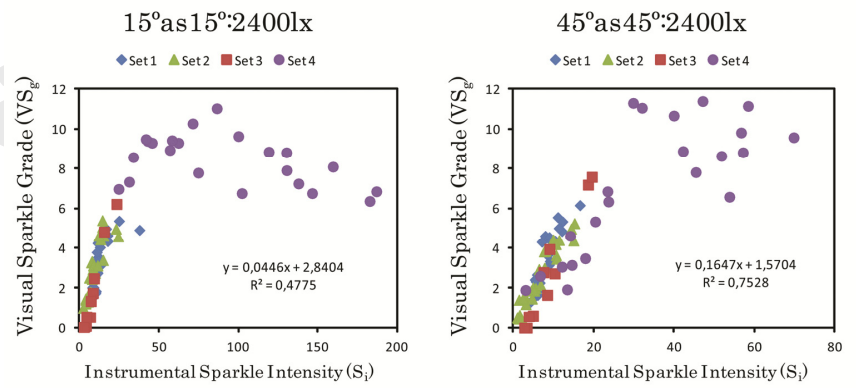

Figure 6: Sparkle intensity correlation for high illumination conditions (2400 lux) for the $15^{\circ}$ as $15^{\circ}$ and $45^{\circ}$ as $45^{\circ}$ measurement geometries.

If Set 4 was removed, linear regression could be applied and a better visual and instrumental correlation was achieved, although it was quite as good for the $15^{\circ}$ as $15^{\circ}$ geometry (Table 2). Observers were asked to evaluate sparkle grade since observers 
had to assign a magnitude between 0 and 10 by considering total sparkle, and not by evaluating the independent variables (sparkle intensity or sparkle area). However, for conventional special effect pigments, there exists a better visual and instrumental correlation, what could indicate that sparkle intensity has a great influence on the sparkle perception.

\begin{tabular}{ccc}
\hline & $800 \operatorname{lux}$ & $2400 \operatorname{lux}$ \\
\hline $15^{\circ}$ as $15^{\circ}$ & $\mathrm{R}^{2}=0.6452$ & $\mathrm{R}^{2}=0.6521$ \\
$45^{\circ}$ as $45^{\circ}$ & $\mathrm{R}^{2}=0.8706$ & $\mathrm{R}^{2}=0.8615$ \\
\hline
\end{tabular}

Table 2: Correlation data $\left(\mathrm{R}^{2}\right)$ of the sparkle intensity correlation for $800 \mathrm{lux}$ and $2400 \mathrm{lux}$, and $15^{\circ}$ as $15^{\circ}$ and $45^{\circ}$ as $45^{\circ}$ without Set 4 .

Sa vs $V_{\mathrm{G}}$ : correlation predictibility from the sparkle area value.

The other factor $\left(S_{a}\right)$ involved in obtaining the sparkle grade equation implemented by BYK-mac was also analyzed. The sparkle area is defined by Standard [2] as "the area segment of the illuminated portion of an object surface with spots that are strikingly brighter than their immediate surround". When compared with the visual results, it was not possible to find a linear correlation between this parameter $\left(\mathrm{S}_{\mathrm{a}}\right)$ and the visual sparkle estimated by the observers, as can be expected looking at Eq. 1. Even when Set 4 was not included, the correlation was not good $\left(\mathrm{R}^{2} \approx 0.5\right)$, and became worse than in the previous subsection for both measurement geometries and for both illumination levels. It was concluded that there was no correlation, and each, group of samples displayed different behaviors and followed different trends (Figures 7 and 8). In this way, it can be concluded that sparkle area has less influence on the sparkle perception. This raises even more questions about the algorithm implemented by BYK-mac because, as we can see above, the general sparkle correlation was fairly good.
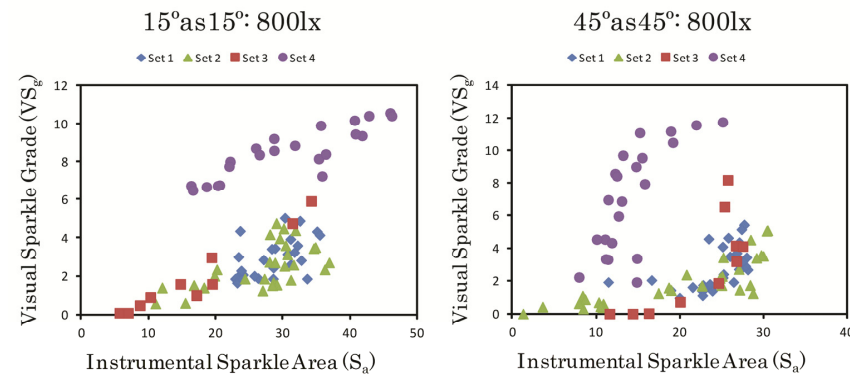

Figure 7: Sparkle area correlation for the low illumination conditions (800 lux) for the $15^{\circ}$ as $15^{\circ}$ and $45^{\circ}$ as $45^{\circ}$ measurement geometries.
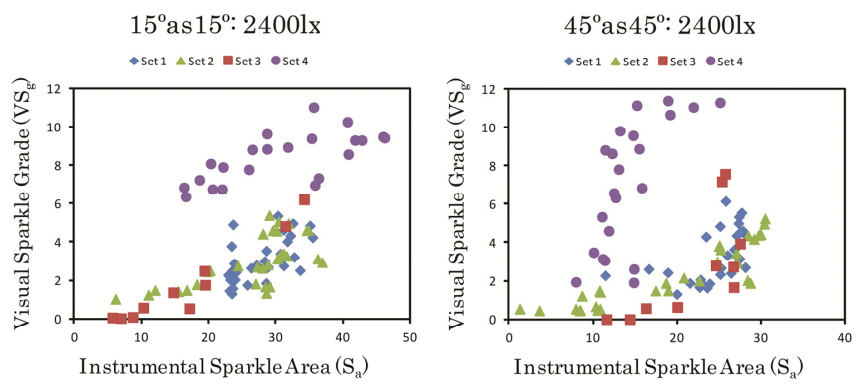

Figure 8: Sparkle area correlation for the high illumination conditions (2400 lux) for the $15^{\circ}$ as $15^{\circ}$ and $45^{\circ}$ as $45^{\circ}$ measurement geometries.

\section{CONCLUSIONS}

A visual experiment was applied to verify whether the instrumental data $\left(\mathrm{S}_{\mathrm{i}}, \mathrm{S}_{\mathrm{a}}, \mathrm{S}_{\mathrm{G}}\right)$ of BYK-mac correlated with the visual sparkle grade estimation made by the observers. Under different conditions, such as illuminance level and geometry, the sparkle magnitude estimation was made by applying a conventional psychophysical method with known pigment sizes and types, but one that included conventional special-effect pigments, and other more recent ones that were not initially included in the current reference sparkle instrument design and validation.

This study tested how sparkle grade $\left(\mathrm{S}_{\mathrm{G}}\right)$ correlated very well with the human visual perception despite using new special-effect pigments (i.e. synthetic mica). In the future it would be interesting to test other new special-effect pigments and samples with similar sparkle effects in other industries, like cosmetics, plastics, etc. Performance was slightly better for the $45^{\circ}$ as $45^{\circ}$ measurement geometry than for the $15^{\circ}$ as $15^{\circ}$ one. Similarly, with a higher illumination level (2400 lux), sparkle was detected slightly better in $45^{\circ}$ as $45^{\circ}$. It was likely that only the first geometry was used, and with a high illuminance level (around 1500 lux), in the original sparkle instrument design and visual validation (BY K-mac).

Sparkle intensity $\left(\mathrm{S}_{\mathrm{i}}\right)$ and sparkle area $\left(\mathrm{S}_{\mathrm{a}}\right)$ did not correlate well with visual perception for any measurement geometry, nor for any illumination level, especially the sparkle area value. This means that although it made sense to wonder about sparkle grade as a general visual assessment, and despite the statistical results, including subset 4 (Luxan, by Eckart), agreeing with this, the final balance between the partial sparkle attributes (Eq. 1) was not valid for new special-effect pigments, which have new shapes and sizes. Therefore, perhaps sparkle perception cannot be modeled by only two gray-level imaging parameters, but by other structural parameters, such as pigment shape and size, concentration, etc., and even by environmental ones like illuminance level, color background, etc., which should be studied and modeled in non linear multi-dimensional models in the short or mid term. Perhaps by applying the statistical design of experiments (DoE) we could enlighten the complex interplay of the structural, environmental, optical and imaging variables involved in sparkle appearance.

Throughout this paper, some possible factors that affect sparkle detection have been discussed, but there are many other factors that probably affect its measurement: surface grade and edge 
roughness; flake thickness, pigment manufacturing, pigment material, reflectivity, refractive index, absorption index, etc.. So the results provided by BYK-mac would be rough approaches, but not accurate ones given the multiple factors involved, and the complexity of generating an algorithm which involves all the factors. Even if this algorithm was generated, other factors of own coating formulations would be influenced, e.g., sample colorimetry, interactions with other pigments, etc.

Work is already being done on several experiments in an attempt to check how they affect the various factors listed above, such as flakes concentration/distribution, sample colorimetry, etc., by applying various experiment designs (DoE) to optimize the results, and to analyze the importance and interaction of factors in sparkle detection.

Acknowledgment. The authors are grateful to the EMRP for funding the project "Multidimensional Reflectometry for Industry". The EMRP is jointly funded by EMRP participating countries within EURAMET and the European Union. We would like to thank the Spanish Ministry of Economy and Competitiveness for coordinated project DPI2011-30090-C02 and project DPI-201568514 and University of Alicante for the project GRE13-28. Omar Gómez Lozano would also like to thank the above-cited ministry for his pre-doctoral fellowship (FPI BES-2012-053080). Finally, we are very grateful to the companies (BASF Coatings, Eckart, Merck) and to W.R. Cramer for their collaboration in providing samples.

\section{References}

1. Klein, G.A. and T. Meyrath, Industrial color physics. Springer, 2010.

2. ASTM E 284-13b. Standard Terminology of Appearance, West Conshohocken, 2013.

3. McCamy, C., Observation and measurement of the appearance of metallic materials. Part I. Macro appearance. Color Research \& Application, 1996. 21(4): p. 292-304.

4. McCamy, C., Observation and measurement of the appearance of metallic materials. Part II. Micro appearance. Color Research \& Application, 1998. 23(6): p. 362-373.

5. Kirchner, E., Van der Lans, I., Perales, E., Martínez-Verdú, F., Campos, J., \& Ferrero, A., Visibility of sparkle in metallic paints. Journal of the Optical Society of America A, 2015. 32(5): p. 921-927.

6. BYK-mac $\mathrm{GmbH}$, Metallic Color, (online:

http://www.byk.com/fileadmin/byk/support/instruments/downloa ds/support-

downloads/public/Manuals/Color/Metallic\%20Color/BYKmac/Detailed\%20manual\%20ENGLISH/269019981_E_0907.pdf; last accessed, June 2016)

7. Dekker, N., Kirchner, E. J. J., Super, R., van den Kieboom, G. J., \& Gottenbos, R., Total appearance differences for metallic and pearlescent materials: contributions from color and texture. Color Research \& Application, 2011. 36(1): p. 4-14.

8. Chorro, E., Perales, E., Burgos, F. J., Gómez, O., Vilaseca, M., Viqueira, V. \& Martínez-Verdú, F. M., The minimum number of measurements for colour, sparkle, and graininess characterisation in gonio-apparent panels. Coloration Technology, 2015. 131(4): p. 303-309.

9. Ferrero, A., Campos, J., Rabal, A. M., \& Pons, A., A single analytical model for sparkle and graininess patterns in texture of effect coatings. Optics express, 2013. 21(22): p. 26812-26819.
10. Kigle-Böckler, G. (2009, January). New and innovative testing technologies for effect finishes. In Color and Imaging Conference (Vol. 2009, No. 1, pp. 91-94). Society for Imaging Science and Technology.

11. Ershov, S., Khodulev, A., \& Kolchin, K. (1999, August). Simulation of sparkles in metallic paints. In Proceeding of Graphicon (pp. 121-128).

12. Höpe, A., Hauer, K. O., Teichert, S., Hünerhoff, D., \& Strothkämper, C. (2015, March). Goniochromatic and sparkle properties of effect pigmented samples in multidimensional configuration. In SPIE/IS\&T Electronic Imaging (pp. 939800-939800). International Society for Optics and Photonics.

13. Segovia, M.V.O., P. Urban, and F.H. Imai, Measuring, Modeling, and Reproducing Material Appearance 2015. Proc. of SPIE-IS\&T Vol, 2015. 9398: p. 939801-1.

14. Huang, Z., H. Xu, and M.R. Luo, Camera-based model to predict the total difference between effect coatings under directional illumination. Chinese Optics Letters, 2011. 9(9): p. 093301.

15. Lex, K., Method and apparatus for the quantitative determination of surface properties. 2012, Google Patents.

16. TARBAM-Project, http://www.eurekanetwork.org/content/e-3037tarbam.

17. Experience the byko-spectra effect cabinet, https://www.youtube.com/watch?v=7j6oBkDKnjE.

18. CIE Publication, Colorimetry, 3rd Edition. Vienna: CIE Central Bureau, 2004.

19. Martínez-Verdú F, Perales E, Viqueira V, Chorro E, Burgos FJ, Pujol J. Comparison of colorimetric features of some current lighting booths for obtaining a right visual and instrumental correlation for gonio-apparent coatings and plastics. Proceedings of CIE 2012 Lighting Quality and Energy Efficiency. 2012. p 692-705.

20. Lu, Z.-L. and B. Dosher, Visual psychophysics: From laboratory to theory. 2013: MIT Press.

21. Knoblauch, K. and L.T. Maloney, Modeling psychophysical data in R. Vol. 32. 2012: Springer Science \& Business Media.

22. Garcia, P. A., Huertas, R., Melgosa, M., \& Cui, G., Measurement of the relationship between perceived and computed color differences. JOSA A, 2007. 24(7): p. 1823-1829.

23. Kirchner, E. and N. Dekker, Performance measures of color-difference equations: correlation coefficient versus standardized residual sum of squares. JOSA A, 2011. 28(9): p. 1841-1848.

24. Melgosa, M., García, P. A., Gómez-Robledo, L., Shamey, R., Hinks, D., Cui, G., \& Luo, M. R., Notes on the application of the standardized residual sum of squares index for the assessment of intra-and inter-observer variability in color-difference experiments. JOSA A, 2011. 28(5): p. 949953.

25. Melgosa, M., Martínez-García, J., Gómez-Robledo, L., Perales, E., Martínez-Verdú, F. M., \& Dauser, T., Measuring color differences in automotive samples with lightness flop: A test of the AUDI2000 colordifference formula. Optics express, 2014. 22(3): p. 3458-3467. 